\title{
Correction to: Fundamental Study on Multistage Extraction Using TDdDGA for Separation of Lanthanides Present in Nd Magnets
}

\author{
YUJI SASAKI, ${ }^{1,4}$ KEISUKE MORITA, ${ }^{1}$ MASAHIKO MATSUMIYA, ${ }^{2}$ \\ RYOMA ONO, ${ }^{3}$ and HIDENOBU SHIROISHI ${ }^{3}$ \\ 1.-Japan Atomic Energy Agency, Tokai, Ibaraki 319-1195, Japan. 2.-Yokohama National \\ University, 79-1 Tokiwadai, Yokohama 240-8501, Japan. 3.-Tokyo National College of \\ Technology, Hachioji, Tokyo 193-0997, Japan. 4.—e-mail: sasaki.yuji@jaea.go.jp
}

\section{Correction to: \\ JOM \\ https://doi.org/10.1007/s11837-021-04586-1}

The article Fundamental Study on Multistage Extraction Using TDdDGA for Separation of Lanthanides Present in Nd Magnets, written by Morita et al., was originally published online on the publisher's internet portal on March 15, 2021 with Open Access under a Creative Commons Attribution (CC BY) license 4.0.
With the author's/authors' decision to cancel Open Access the copyright of the article changed on March 19, 2021 to (c) The Minerals, Materials \& Metals Society 2021 with all rights reserved.

Publisher's Note Springer Nature remains neutral with regard to jurisdictional claims in published maps and institutional affiliations. 